\title{
UMA ANÁLISE COMPARADA DE FLANNERY O’CONNOR E LYA LUFT
}

\author{
DÉBORA BALLIELO BARCALA (UNESP/Assis) ${ }^{1}$
}

\begin{abstract}
RESUMO: O presente trabalho tem por objetivo apresentar uma análise comparada das personagens femininas Hulga/Joy do conto "Good Country People" (1955), de Flannery O'Connor, e Dolores/Dôda do romance O tigre na sombra (2012), de Lya Luft, em uma aproximação inédita. As semelhanças entre as personagens vão desde a deformidade física e a complicada relação mãefilha, até a duplicidade de nomes e a percepção de si mesmas como seres ambivalentes. Apesar de viverem conflitos e experiências diferentes, ambas as personagens retratam experiências vividas por muitas mulheres em sociedades patriarcais. Assim, este artigo propõe uma leitura do conto de O'Connor e do romance de Luft como críticas aos papeis de gênero e à sociedade patriarcal construída por meio das imagens e personagens grotescas, bem como uma discussão sobre as possibilidades feministas nas obras das autoras.
\end{abstract}

PALAVRAS-CHAVE: Personagem feminina, Flannery O'Connor, Lya Luft, Literatura Comparada, grotesco feminino.

ABSTRACT: This work aims to present a comparative analysis of the characters Hulga/Joy from the short story "Good Country People" (1955), by Flannery O'Connor, and Dolores/Dôda from the novel O tigre na sombra (2012), by Lya Luft, in an unprecedented approximation. The similarities between the characters range from the physical deformity and the complex mother-daughter relationship to the duplicity of names and the perception of themselves as ambivalent. Despite different conflicts and experiences, both characters depict common experiences to many women living in patriarchal societies. Therefore, this article proposes a reading of O'Connor's short story and Luft's novel as critiques to gender roles and patriarchal society built based on grotesque images and characters, as well as a discussion about the feminist possibilities in the authors' works.

KEYWORDS: Female character, Flannery O'Connor, Lya Luft, Comparative Literature, female grotesque.

\section{INTRODUÇÃO}

Em seu livro A Intertextualidade (2008), Tiphaine Samoyault discute a melancólica afirmação de La Bruyère de que "Tudo está dito, e chegamos demasiado tarde, há mais de sete mil anos que há homens, e que pensam" (apud SAMOYAULT, 2008, p. 68). De acordo com a autora, essa afirmação foi feita na primeira edição dos Caractères, de 1688, no entanto, podemos rastrear este sentimento humano de que nada há de original ainda por fazer em textos ainda mais antigos, reforçando a ideia de La Bruyère:

Toda palavra é enfadonha e ninguém é capaz de explicá-la. O olho não se sacia de ver, nem o ouvido se farta de ouvir. O que foi, será, o que se fez, se tornará a fazer: nada há de novo debaixo do sol! Mesmo que alguém afirmasse de algo: "Olha, isto é novo!", eis que já sucedeu em outros tempos muito antes de nós (Eclesiastes 1:8-10).2

Desde a época do Eclesiastes e também de La Bruyère, permanece a sensação de que dividimos experiências e sentimentos com as civilizações antigas de que a vida é um eterno retorno. Ainda assim, o ser humano tem tentado exprimir essa melancolia ao longo de séculos

\footnotetext{
1 Doutoranda em Literatura e Vida Social pela UNESP, campus de Assis, sob orientação da doutora Cleide Antoria Rapucci, pesquisa financiada pela FAPESP, e-mail: db.barcala@gmail.com.

2 Bíblia de Jerusalém.
} 


\section{$=$ TRAMA $=$}

por meio das palavras e, embora nunca o faça por definitivo, "os ouvidos não se enchem de ouvir". Não nos cansamos de ouvir histórias sobre a mesma temática porque temas como amor, amizade, morte, tristeza, medo continuam relevantes e são constantemente adaptados às mudanças tecnológicas, sociais e históricas pelas quais passamos.

Dessa forma, conforme nos explica Samoyault (2008), além de se propor como uma forma de transmissão de sensações, pensamentos e experiências, a literatura também é a "retomada, a adaptação de um mesmo assunto a um público diferente" (SAMOYAULT, 2008, p. 75) e, portanto, a literatura contemporânea faz sempre lembrar a literatura que foi produzida anteriormente. É por esse motivo que é tão difícil comprovar "crimes" como o roubo de uma ideia, já que esta é algo imaterial e que não pertence a alguém. Além disso, é importante destacar, como o faz Samoyault (2008, p. 70), que a originalidade, isto é, o ato literário criativo não está presente na matéria ou na ideia que veicula, mas sim no encontro da ideia e da maneira como esta é transmitida.

A esse movimento auto referencial da literatura, Samoyault (2008) dá o nome de "memória da literatura". Esta memória está, evidentemente, carregada de material já escrito, já dito que perpassa também as memórias individuais de quem ouve ou lê uma história, no entanto, esta combinação possui sempre potencialidade para gerar uma obra nova. Assim, a "memória da literatura atua em três níveis que não se recobrem jamais inteiramente: a memória trazida pelo texto, a memória do autor e a memória do leitor" (SAMOYAULT, 2008, p. 143). O processo de escrita consiste, assim, num processo também de reescrita que colabora para a contínua recriação de algum tema ou mensagem.

No presente artigo, nos propomos a apontar algumas semelhanças de temas e motivos na representação da figura feminina grotesca entre as obras da autora norte-americana Flannery O'Connor e da brasileira Lya Luft que desvelam preocupações e anseios semelhantes entre os dois contextos sócio culturais em que as escritoras estavam inseridas.

Mary Flannery O'Connor nasceu em 1925, na Geórgia, sul dos Estados Unidos, e ali viveu a maior parte de sua vida. Graduou-se em Ciências Sociais e iniciou sua carreira literária durante a pós-graduação: mestrado em escrita criativa em lowa, um dos cursos pioneiros nessa área. A autora faleceu com apenas 39 anos, em 3 de agosto de 1964, mas deixou uma obra de dois romances e duas coletâneas de contos, além de vários ensaios e cartas, reunidos e publicados postumamente. Sua obra, assim como a da maioria dos escritores do sul dos Estados Unidos à época, é geralmente inserida no Southern Gothic, ou gótico sulista, e encarada como grotesca.

Lya Fett Luft, por outro lado, nasceu em Santa Cruz do Sul, no estado do Rio Grande do Sul, em 1938. Graduou-se em Pedagogia e em Letras Anglo-Germânicas e trabalhou como tradutora do inglês e do alemão por vários anos. Luft também foi professora universitária, lecionando na Faculdade Porto-Alegrense, na área de Linguística. Publicou seu primeiro romance, As parceiras, em 1980 e desde então já publicou vários romances, livros infantis, coletâneas de ensaios, crônicas e poemas. O objeto deste artigo é seu último romance, O tigre na sombra, publicado em 2012.

Apesar da distância geográfica e temporal entre as duas autoras, existem alguns pontos de contato entre a obra de O'Connor e de Luft, especialmente no que diz respeito à utilização de elementos grotescos para evidenciar características da personalidade e da vida interior de suas personagens. Não há evidências de que Lya Luft tenha entrado em contato com a obra de Flannery O'Connor, no entanto, a partir de algumas aproximações trazidas ao longo do artigo, é possível perceber que ambas as autoras apresentam aspectos convergentes da experiência feminina, resultado talvez de semelhanças culturais entre os dois países, de um chão cultural compartilhado, ou do chamado Zeitgeist. E aqui retomamos Samoyault (2008, p. 


\section{$=$ TRAMA $=$}

74) para destacar que, assim como acontecia entre os autores antigos como Sófocles e Eurípides, é perfeitamente possível que dois escritores modernos distintos se apropriem de assuntos que pertencem à tradição coletiva e os abordem quase que concomitantemente.

Conforme afirma Kaiser (1989, p. 229), alguns "temas e motivos mantêm-se frequentemente através de séculos ou mesmo milénios de formações literárias e sociais diversas". E além de serem usados em épocas distintas para tratar de diversas temáticas, os autores lançam mão de temas e motivos diferentes para tratar da mesma temática. Dessa forma, conforme afirmam Machado e Pageaux (1988), o estudo dos temas em literatura deve transcender a ideia de temas universais para tratar de elementos recorrentes que são "reinvestidos simbolicamente de diferentes maneiras, segundo o espaço cultural e o momento histórico analisado" (MACHADO; PAGEAUX, 1988, p. 117).

Mas convém definir o que queremos dizer com o vocábulo "tema", já que este é usado com muitos sentidos diferentes e em situações cotidianas. Quando tratamos de temas, estamos, claramente, nos referindo não apenas ao conteúdo do texto, mas também ao fio condutor, isto é, ao princípio produtor do texto. Neste sentido "deverá chamar-se tema a tudo aquilo que é elemento constitutivo e explicativo do texto literário, elemento que ordena, gera e permite produzir o texto" (MACHADO; PAGEAUX, 1988, p. 117). O tema é, portanto, aquilo que Machado e Pageaux (1988) chamam de elemento mediador e fundador, pois media a relação entre o ser humano e sua cultura e funda o texto de forma a relacioná-lo ao imaginário coletivo e individual, ou, em outras palavras, o tema pode ser aquilo que une um texto à memória da literatura, nos níveis do texto, do leitor e também do autor.

Analisar o tema, portanto, não implica apenas em abordar o assunto de que trata um determinado texto literário, mas também de estudar como essa ideia se relaciona com a estrutura da obra e com o contexto em que foi produzida. O estudo do tema no âmbito da Literatura Comparada tem a vantagem, então, de oferecer pistas sobre aquilo que transcende uma determinada cultura e se transforma em uma preocupação de duas ou mais culturas ou comunidades literárias, conforme nos explica Poulet: "La critique thématique peut encore nous révéler ce qui se transmet d'une pensée à d'autres, ce qui se découvre em diverses pensées comme étant leur principe ou leur fond commun" (POULET apud MACHADO; PAGEAUX, 1988, p. 119).

Neste trabalho, abordaremos apenas as semelhanças e diferenças entre as trajetórias de duas personagens femininas: Joy/Hulga, de "Good Country People" (1955), de Flannery O'Connor e Dolores/Dôda, de O tigre na sombra (2012), de Lya Luft.

A primeira semelhança a chamar a atenção entre as duas protagonistas é a deformidade física na perna. Enquanto Joy/Hulga teve parte de sua perna amputada com dez anos de idade em um acidente de caça e, por isso, usa uma prótese, Dolores/Dôda tem uma perna mais curta do que a outra.

Vemos aqui, também, a primeira diferença entre elas, já que a protagonista de O'Connor perde parte de seu corpo de forma violenta e traumática, diferentemente da protagonista de Luft que sempre teve uma diferença física, a qual não era fruto de violência. O narrador de "Good Country People" nos informa que Hulga era "loura e corpulenta, mas com uma perna de pau"3 (O'CONNOR, 2008, p. 346), que permitia a ela certa mobilidade, já que sua "perna fora literalmente esfacelada"4 (O'CONNOR, 2008, p. 350) ao ser "atingida por um tiro, num acidente de caça, quando Allegra tinha dez anos"5 (O'CONNOR, 2008, p. 348). A prótese de Hulga,

\footnotetext{
3 “a large blonde girl who had an artificial leg" (O'CONNOR, 1988, p. 263)

4 "had been literally blasted off" (O'CONNOR, 1988, p. 267)

5 "shot off in a hunting accident when Joy was ten" (O'CONNOR, 1988, p. 266)
} 


\section{$=$ TRAMA $=$}

além de uma evidência de sua deformidade, é o que lhe possibilita um grau de independência e mobilidade de forma que:

Era, porém, tão suscetível no tocante à perna de pau quanto um pavão em relação à própria cauda. Ninguém jamais tocava nela, a não ser ela mesma, que cuidava da perna como outros cuidam da alma, em total privacidade e quase voltando os olhos para longe do alvo (O'CONNOR, 2008, p. 366). ${ }^{6}$

Já Dôda, que além de protagonista, é também a narradora, não tem certeza da origem de sua deformidade física, pois a princípio relata: "Além do mais nasci com esse defeito: uma de minhas pernas é mais curta do que a outra. Não é muito, mas eu ando de um jeito feio, levemente inclinada para um lado. Para algumas pessoas, como minha mãe, esse defeito me classifica" (LUFT, 2012, p. 15). E mais tarde na narrativa afirma que:

Nunca me contaram direito a origem dessa minha deficiência física: minha mãe dizia que eu tinha nascido assim, por azar dela, mas havia quem dissesse que ela tinha me deixado cair logo nos primeiros dias. Uma de minhas pernas era mais curta do que a outra. Não era propriamente um aleijão, mas me tornava diferente. Meu corpo entortado. Meu andar feioso, e minha parceira, a dor (LUFT, 2012, p. 27).

Essas características das pernas das protagonistas são extremamente importantes para o desenvolvimento da narrativa podendo, neste sentido ser considerados elementos estruturais. Ambas as personagens são percebidas e definidas tanto pelos outros como por si mesmas como diferentes e grotescas devido a seu aspecto físico. É devido à prótese que Hulga vai se envolver com um suposto vendedor de Bíblias que aparece em sua fazenda e que, mais tarde, após tê-la enganado, rouba sua prótese deixando-a imóvel no celeiro. É também devido à perna mais curta que Dôda acredita não ser amada pela mãe, o que afeta sua autoestima e todos os seus relacionamentos posteriores.

Assim, os corpos de Hulga e Dôda são inacabados, imperfeitos, opostos a tudo aquilo que se considera como belo pela estética clássica e, assim sendo, são corpos grotescos conforme definido por Bakhtin (2013, p. 278): "o grotesco ignora a superfície sem falha que fecha e limita o corpo, fazendo dele um fenômeno isolado e acabado".

No entanto, as deformidades físicas são ambivalentes para as personagens, isto é, não são aspectos puramente negativos. A prótese de Hulga permite que ela tenha mobilidade, ainda que limitada e, de acordo com a irmã de Dôda, Dália, sua perna mais curta também Ihe garante certa liberdade: "- Mana, você não sabe o quanto eu te invejei, porque sua perninha doente te dava liberdade: de você a mãe não exigia quase nada, não esperava grande coisa. Por sorte sua, Dôda, repito que essa perna te libertou. (LUFT, 2012, p. 71)".

De acordo com Gilbert e Gubar (2000), até o século XIX as representações femininas feitas por homens dividiam-se entre mulheres-anjo e mulheres-monstro, entre a mulher que desperta o desejo contemplativo e platônico e a mulher que desperta o medo. É essa a diferença fundamental da exposição corporal realizada pelas mulheres na literatura: não se trata mais de mulheres-objeto ou mulheres abjetas, mas de mulheres que são vítimas de uma visão patriarcal reducionista e de mulheres que buscam sua independência e seu caminho no mundo.

\footnotetext{
${ }^{6}$ But she was as sensitive about the artificial leg as a peacock about his tail. No one ever touched it but her. She took care of it as someone else would his soul, in private and almost with her own eyes turned away. (O'CONNOR, 1988, p. 281).
} 


\section{$=$ TRAMA $=$}

No contexto da literatura sulista norte-americana de autoria feminina, Yaeger (2000) comenta que o grotesco sempre foi encarado como uma visão pessimista sobre a sociedade, que procurava evidenciar a capacidade humana para o mal e a decadência moral do Sul. Isto, no entanto, não parece ser o suficiente para explicar o uso constante do grotesco por autoras de contextos sociais, econômicos e raciais distintos. Para a estudiosa, na escrita feminina sulista norte-americana, há um predomínio "de carne que foi rompida ou destroçada por violência, de corpos fraturados, excessivos dizendo-nos algo que as diversas culturas sulistas não querem que falemos" (YAEGER, 2000, p. xiii). Os corpos irregulares, incompletos, extravagantes do grotesco feminino sulista são transgressores, pois estão inseridos em uma sociedade extremamente reguladora. Assim, Yaeger (2000, p. xi) defende que a abordagem da literatura sulista feminina deve mudar; em lugar da belle ou da "mulher 'em miniatura' como protótipo da figura feminina sulista" coloca-se uma "procissão de mulheres gigantes".

Dessa forma, fica evidente que O'Connor e Luft realizam uma escrita que dá ênfase ao corpo, não necessariamente como um espaço de celebração, no entanto. O corpo de suas personagens é o espaço de absorção do impacto das forças sociais que tentam controlá-lo. Forças patriarcais especialmente representadas pelas figuras dos homens e das mães que reproduzem discursos opressores, como é o caso da mãe de Dôda:

- Caminha direito, menina.

- Mas mãe, eu não consigo andar direito.

- Então caminha menos torto.

Eu me esforçava, segurando o choro e a raiva (LUFT, 2012, p. 35).

Com esse impacto, as personagens femininas sofrem, com frequência, de colapsos físicos "sugerindo uma desarticulação entre as arenas social, intelectual e física das vidas das mulheres" (VERDERAME, 2000, p. 147).

Ambas as protagonistas percebem a si mesmas como duplas, isto é, como tendo duas personalidades opostas dentro de si mesmas. No caso de "Good Country People", essa percepção fica evidenciada pela mudança do nome que a personagem faz aos vinte e um anos de idade, de Joy (Allegra) para Hulga. Hulga escolhe o nome mais oposto a tudo aquilo que Joy (Allegra) representava, numa tentativa de afastar-se do ideal da mãe, pois se sente rebaixada dele, e também numa tentativa de individuação. O narrador nos informa que, para Hulga, "um de seus grandes triunfos era o fato de sua mãe não ter sido capaz de transformar seu próprio pó em Allegra, se bem que o maior de todos fosse ela mesma ter podido transformá-lo em Hulga"' (O'CONNOR, 2008, p. 350).

Harvid (1993) defende que Hulga é uma das personagens de O'Connor que tenta se aproximar da condição masculina, fugindo do código de conduta esperado dela, sendo independente, dominadora e orgulhosa. Para ele, Hulga tenta se transformar intelectualmente num homem, enxergando a si mesma como o deus Vulcano, deformado e aleijado:

O novo nome era considerado por ela uma questão pessoal. Chegara a ele, a princípio, apenas levando em conta a fealdade do som, mas depois veio a notar todo o espírito de sua adequação. Tinha tido a inspiração desse nome ao trabalhar como o feio e suarento Vulcano, que se mantinha à forja e que supostamente a Deusa iria visitar quando invocada, tomando-o mesmo pelo nome de seu ato criador mais excelso (O'CONNOR, 2008, p. 349-350). ${ }^{8}$

\footnotetext{
7 "One of her major triumphs was that her mother had not been able to turn her dust into Joy, but the greater one was that she had been able to turn it herself into Hulga" (O'CONNOR, 1988, p. 267).

${ }^{8}$ She considered the name her personal affair. She had arrived at it first purely on the basis of its ugly sound and then the full genius of its fitness had struck her. She had a vision of the name working like the ugly
} 


\title{
$=$ TRAMA $=$
}

Assim, Hulga se via como o deus coxo da mitologia, marido traído de Vênus, deusa da beleza e do amor. Nesse sentido, podemos afirmar que a personagem enxergava em si mesma uma parte que identificava como masculina e dominante e uma parte feminina que é representada no conto pelo nome Joy, que carrega em si todas as expectativas da mãe e todos os padrões de condutas esperados de uma mulher. Hulga deliberadamente transforma-se em Vulcano ao trocar seu nome, embora mantenha a deusa Joy à disposição, demonstrando aquilo que Gentry (1986) afirma ser a característica primordial do grotesco: o sentimento de estar degradado de um ideal, mas ainda sentir-se atraído por ele. No caso, a deusa Vênus representa o ideal da mãe para a filha, como uma referência de feminilidade pautada pela sensualidade $e$ pelo amor a um homem. A personagem vive permanentemente na fronteira entre o considerado masculino e o feminino.

Da mesma maneira, Dôda percebe a si mesma como ambivalente, embora não identifique cada uma de suas partes como masculina ou feminina. Apesar de não mudar legalmente seu nome, Dôda adota um apelido para se diferenciar de Dolores, nome escolhido pela mãe que considera lúgubre, triste.

\begin{abstract}
Para narrar esta trama convoquei duas metades que formam uma só personagem, gêmeas siamesas que nem sabem direito por onde estão unidas, e não importa. Talvez unidas pela diferença: no espelho, Dolores, sensual, engraçada, às vezes maldosa. Ou imitando os passos de balé de minha irmã amada. Do lado de cá, eu, Dôda, a menina da perna curta, naquele desassossego querendo saber, entender, viver, e ser menos desajeitada.

Então eu era mais que uma, duas. Ou muitas, pois com o correr do tempo eu descobria, aqui e ali, dentro de mim e dos outros, alguém totalmente inesperado. Não somos todos assim, certos e errados e bons e diabólicos e perdidos e reencontrados? (LUFT, 2012, p. 18-19).
\end{abstract}

Dôda era, então, a parte da personagem que constantemente tentava agradar a mãe e se ajustar aos padrões impostos pela sociedade, sem nunca obter sucesso. Dôda era sua parte correta, recatada, que tentava ignorar sua diferença, mas que era sempre ferida pelos outros. Dolores, por sua vez, era sua parte que não se submetia à vontade dos outros, que não tentava se encaixar nos padrões, mas que também só era conhecida da própria personagem, pois ela nunca desvelou esse seu lado a ninguém.

Dôda e Dolores são duas. Sou duas. A transgressora que abre braços e pernas e se derrama de dentro do obscuro caldeirão das minhas fantasias, e a cumpridora que aqui não sabe viver. Dolores sempre espreitou tudo, rindo sozinha. Dôda morria a cada hora, de abandono e rejeição. (LUFT, 2012, p. 23).

De acordo com Bakhtin (2013, p. 21) "a imagem grotesca caracteriza um fenômeno em estado de transformação, de metamorfose ainda incompleta, no estágio da morte e do nascimento, do crescimento e da evolução". Ou seja, o grotesco é sempre um processo, a representação de algo que está em mutação. Daí a constante representação de corpos abertos, incompletos, como é o caso das personagens aqui analisadas. Ambas estão no meio de um processo de autoconhecimento e, em decorrência disso, são ambivalentes, pois a ambivalência é o segundo traço indispensável da imagem grotesca (Bakhtin, 2013, p. 22). Isto significa dizer que "os dois polos da mudança - o antigo e o novo, o que morre e o que nasce, o princípio e o fim da metamorfose - são expressados (ou esboçados) em uma ou outra forma" (BAKHTIN, 


\title{
$=$ TRAMA $=$
}

2013, p.22, grifo do autor). Assim, ambas as personagens podem ser consideradas grotescas também por sua ambivalência.

Além dos aspectos já mencionados, as duas filhas, Hulga e Dôda, sentem-se degradadas em relação aos ideais das mães para elas. Hulga é caracterizada no conto principalmente em oposição a outras personagens femininas consideradas como "mais adequadas" ao papel relegado às mulheres naquele contexto sociocultural. Sua mãe, Mrs. Hopewell "dizia de bom grado aos outros que Glynese e Carramae [filhas de Mrs. Freeman] eram duas das melhores moças que já conhecera, que Mrs. Freeman era uma dama e que ela jamais se envergonharia de levá-la em sua companhia"9 (O'CONNOR, 2008, p. 346). A mesma Mrs. Hopewell, no entanto, envergonha-se do grau de educação da filha, conforme nos informa o narrador:

\begin{abstract}
A menina doutorou-se em filosofia e isso deixara Mrs. Hopewell no mais completo embaraço. Qualquer um bem podia dizer "Minha filha é enfermeira", ou "Minha filha é professora do ensino básico", ou até mesmo "Minha filha é engenheira química". Mas quem diria "Minha filha é filósofa", se isso era coisa morta e acabada desde os romanos e os gregos? (O'CONNOR, 2008, p. 351-352). ${ }^{10}$
\end{abstract}

De acordo com Babinec (1990) o doutorado de Hulga não se encaixa nas expectativas de Mrs. Hopewell de que a filha cumprisse um papel social de mãe e esposa. Da mesma forma, a mãe de Dôda compara a filha constantemente à irmã Dália, considerada a menina ideal, a filha perfeita que seria bailarina e com quem Dôda não poderia competir, devido à sua personalidade e à sua perna mais curta. Dôda sente-se rejeitada, degradada dos ideais da mãe para ela:

\footnotetext{
Minha mãe, que não me amava, teve duas filhas:

A primeira chamou Dália, como num romance lido anos atrás. Queria dar a todas as filhas mulheres nomes de flor. [...]

Ela parou em Dália, que era alegre e doce, fácil de criar, a mãe dizia, e se tornou a adolescente belíssima com olhos negros onde apareciam lasquinhas de ouro quando ela ria. A mãe amou aquela filha até o fim, por todos os descaminhos, com um amor obsessivo que acabou por a afastar. (LUFT, 2012, p. 14)
}

A mãe de Dôda já estabelece a distinção entre as filhas com os próprios nomes. Dália, a filha ideal, tinha nome de flor, já Dôda, a filha que simbolizava sua frustração, tem um nome que remete à dor: "A mãe me chamou Dolores. Nome escuro, de sombra e pranto, cheio de ôôôs lúgubres. Escolheu esse nome porque, dizia, sofreu muito para me botar no mundo. Eu Ihe dei trabalho desde a hora de nascer, e sempre daria, porque nasci do jeito que sou" (LUFT, 2012, p. 15).

Neste sentido, podemos estabelecer uma diferença entre Mrs. Hopewell, mãe de Hulga, e a mãe de Dôda: enquanto aquela escolhe um nome belo para sua filha, que remetia à alegria e ao regozijo, esta escolhe um nome triste, lúgubre. Já no nascimento das filhas vemos, portanto, a diferença de expectativas das mães. De Joy/Hulga, que nasce sem nenhum defeito físico aparente, Mrs. Hopewell espera uma filha ideal, alegre e condizente com os padrões sociais. Por outro lado, ao ver a filha que, ao que tudo indica, nasceu com uma perna mais

\footnotetext{
9 "liked to tell people that Glynese and Carramae were two of the finest girls she knew and that Mrs. Freeman was a lady and that she was never ashamed to take her anywhere" (O'CONNOR, 1988, p. 264).

${ }^{10}$ The girl had taken the Ph.D. in philosophy and this left Mrs. Hopewell at a complete loss. You could say, "My daughter is a nurse," or "My daughter is a school teacher," or even, "My daughter is a chemical engineer." You could not say "My daughter is a philosopher." That was something that had ended with the Greeks and Romans. (O'CONNOR, 1988, p. 268).
} 


\title{
$=$ TRAMA $=$
}

curta, a mãe de Dôda já espera dificuldades e uma vida de sofrimento pela frente, embora ainda tente moldá-la de acordo com seus ideais:

\begin{abstract}
- Senta direito. Não fica tanto no sol. Não lê demais ou ainda por cima vai ter de usar óculos. Não caminha assim. Não usa essa palavra. Não dorme demais. Não come demais. Olha os modos. Cala a boca. Não responde. Vai pentear seu cabelo. É vermelho mas ao menos tem de estar bem penteado. Olha a mancha no seu vestido. Você é sempre desajeitada. Nunca faz nada direito (LUFT, 2012, p. 41).
\end{abstract}

A verdade é que ambas as mães são frustradas com os caminhos que as filhas escolheram para si e não conseguem aceitá-las justamente por serem de um "tipo" diferente. De acordo com Babinec (1990), algumas mães consideram baixo status social das filhas como falha pessoal. Assim, quando as filhas não conseguem alcançar os padrões definidos por um grupo social, "um sentimento de falha materna e incompetência se desenvolve e leva à angústia e a um sentimento de impotência e culpa, sentimentos que provocam relações mãe-filha voláteis" (BABINEC, 1990, p. 15, tradução nossa). Numa tentativa de compensar esse sentimento de falha, as mães alimentam expectativas altas para suas filhas que, quando frustradas, geram insatisfação e raiva levando a maior isolamento entre mãe e filha. As filhas, por outro lado, também têm expectativas em relação às mães, as quais igualmente não conseguem atingi-las. Portanto, "mais uma vez um padrão cíclico de falha e desapontamento existe entre as duas" (BABINEC, 1990, p. 16, tradução nossa).

Enquanto Hulga se frustra com o fato de a mãe não aceitá-la como é, sempre tentando fazer com que sorria mais e saia mais de casa para caminhar pela fazenda, ao invés de passar boa parte dos seus dias lendo, Dôda também se frustra por não conseguir atingir as expectativas sociais da mãe e acaba por internalizar o discurso desta: "A mãe tinha razão. Eu nem conhecia os naipes do baralho que ela curtia com as amigas, não poderia nunca dançar, nem correr, nem seria elegante ou bonita. Não ia namorar, casar, ter lindos filhos. /Quem ia querer uma moça assim meio tortinha?" (LUFT, 2012, p. 37).

Ambas as mães acabam por se transformar em mães terríveis, ou mães castradoras, devido à suas obsessões em controlar as filhas para que elas se aproximem daquilo que consideram "normal":

\begin{abstract}
Mrs. Hopewell desculpava a atitude devido à perna da filha (atingida por um tiro, num acidente de caça, quando Allegra tinha dez anos). Para ela não era nada fácil compreender que a menina estava agora com trinta e dois anos e há mais de vinte tinha uma perna apenas. Considerava-a ainda uma criança por sentir seu coração dilacerar-se ao pensar que a pobre moça, cheia de viço e já com aquela idade, nunca sequer dera um só passo de dança ou tivera bons momentos de maneira normal. (O'CONNOR, 2008, p. 348-349). ${ }^{11}$
\end{abstract}

Dôda chega até mesmo a passar por uma cirurgia e por um doloroso processo de recuperação, na tentativa inútil de sua mãe de mudar sua perna:

Depois a perna presa em ferros, intermináveis fisioterapias que me faziam chorar, e a obsessão de minha mãe para que eu fizesse tudo direito e logo ficasse normal.

\footnotetext{
${ }^{11}$ Mrs. Hopewell excused this attitude because of the leg (which had been shot off in a hunting accident when Joy was ten). It was hard for Mrs. Hopewell to realize that her child was thirty-two now and that for more than twenty years she had had only one leg. She thought of her still as a child cause it tore her heart to think instead of the poor stout girl in her thirties who had never danced a step or had any normal good times. (O'CONNOR, 1988, p. 266).
} 


\section{$=$ TRAMA $=$}

Ela queria uma filha normal.

Eu nunca fiquei normal.

Ela estava cumprindo seu dever de mãe, dizia quando eu me rebelava. Nunca deixaria de mencionar o quanto se sacrificava por mim, e no quanto foi prejudicada pelas despesas comigo, porque meu pai pagou médico particular, hospital particular, gastando o dinheiro guardado para uma viagem com ela. (LUFT, 2012, p. 28).

Todos os exemplos expostos até agora exemplificam de que forma as duas escritoras utilizam elementos e aspectos do grotesco na caracterização de suas personagens femininas para evidenciar o quanto elas não se encaixam nos padrões físicos, emocionais e familiares impostos a uma mulher desde a infância. É evidente, portanto, a importância das representações de mulheres, feitas por mulheres, para revelar as opressões do patriarcado e o grotesco é um elemento que as ajuda nesta tarefa.

De acordo com Gentry (1986), o grotesco pode ser entendido como uma degradação, ou rebaixamento de um ideal, embora mantenha sempre uma relação com este mesmo ideal. O grotesco pode ser percebido nas ações das personagens que enxergam a si mesmas como degradadas. Embora o enfoque do estudo de Gentry seja no grotesco religioso, "sua definição pode ser entendida como pertencente à degradação de qualquer ideal social ou cultural, e seu conceito de grotesco é igualmente aplicável ao 'grotesco feminino'" (CARUSO, 2001, p. 12, tradução nossa). Nas obras de O'Connor e Lya Luft, o grotesco feminino demonstra, através do degradado, os ideais de gênero que oprimem as mulheres.

O traço distintivo e fundamental do grotesco, com o qual a maioria dos autores concorda, é o rebaixamento ou a degradação de um ideal. Este ideal normalmente era tomado como algo religioso ou espiritual, mas, quando levamos em conta o grotesco feminino, podemos perceber que o grotesco das personagens femininas de O'Connor e Luft deriva muito mais da degradação de ideais culturais e sociais, "particularmente daqueles referentes aos construtos do paradigma de feminilidade (sulista) e ao lugar da mulher na sociedade" (CARUSO, 2004, p.3, tradução nossa).

O uso do grotesco em associação ao feminino feito especialmente por escritoras tornase uma estratégia de reconhecimento perante a crítica e o mercado, já que contradiz "a tradição visual e decorativa que remete a um 'feminino idealizado'" (CRIPPA, 2003, p. 113). Assim, se é esperado da mulher uma produção artística delicada, sutil e bela, o grotesco feminino "fornece uma abertura para uma expressão sexuada e anticonformista das artistas" (CRIPPA, 2003, p. 113) e quebra com as expectativas questionando a realidade dos movimentos clássicos, que se pretendem racionais e coerentes.

Conforme afirmam Machado e Pageaux (1988, p. 120-121), realizar o estudo temático de uma obra revela não apenas o funcionamento interno de um texto, mas também o estudo da função social deste mesmo texto, que são "as duas fases indissociáveis da investigação literária" (MACHADO; PAGEUAX, 1988, p. 121). Portanto, neste artigo procurou-se destacar o papel fundamental do grotesco na estrutura interna das obras de O'Connor e de Lya Luft e seu papel social contestatório da verdade (ou mentira) oficial que é responsável pela manutenção do status-quo. Destruindo "o quadro oficial da época e dos seus acontecimentos" (BAKHTIN, 2013, p. 386), as obras das autoras lançam um novo olhar sobre a situação das mulheres em sua época, revelando o quanto o sistema patriarcal as oprime e vitima e enfatizando a insuficiência da sociedade patriarcal em organizar o mundo.

Embora as personagens femininas não tenham finais felizes (Hulga acaba isolada no alto do celeiro e sem a prótese e Dôda acaba isolada na casa da avó, traída pelo marido e pela irmã), nem proclamem abertamente um discurso feminista, nas obras das autoras os conflitos 


\section{$=$ TRAMA $=$}

de gênero são expostos, bem como a tentativa das mulheres de buscar seu caminho próprio. Ainda que esse caminho acabe no "beco sem saída" de que fala Elódia Xavier (1999) em seu texto sobre as fases da literatura feminina elencadas por Showalter aplicando-as na literatura brasileira de autoria feminina. Ao falar sobre Lya Luft, que é colocada pela autora na fase feminista, Xavier afirma que "o trágico e o grotesco se articulam para desvelar as regras desse jogo sujo, onde a mulher é sempre perdedora" (1999, p. 6). Nesse sentido, Xavier (1999) reitera a afirmação de Costa (1996) de que, "ao colocar como protagonista desta saga a mulher na sua condição de perdedora, vítima desse destino cultural” (COSTA, 1996, p. 13), os textos de Lya Luft representam uma denúncia, um questionamento dos conflitos do universo feminino.

De acordo com Wilson (2004, p. 96, tradução nossa), uma "das principais maneiras com que a ficção de O'Connor demonstra uma falta de fé na ordem patriarcal é por meio de seu desfile de personagens excêntricas e não conformistas". Acreditamos, assim como o faz Feitosa (2011, p. 55), que esta afirmação também é verdadeira em relação à obra de Luft: "as personagens na obra de Luft se contrapõem aos normais em diversas categorias, seja pelos corpos 'imperfeitos', pelos comportamentos pouco ortodoxos ou pelos problemas mentais". Neste desfile de personagens excêntricas figuram desde radicais religiosos a mulheres que não desejam ter filhos, de meninas andróginas a senhoras casadas controladoras, de aberrações a portadores de deficiência. A maioria das personagens das autoras é composta por desajustados sociais.

Ao focalizar em tais personagens que estão às margens do padrão, "as histórias de O'Connor revelam os parâmetros limitadores de sua região e época, bem como do patriarcado em geral" (WILSON, 2004, p. 96, tradução nossa). Segundo Giannone (1996, p. 74, tradução nossa), todas as personagens de O'Connor "estão fora da circunferência da definição da sociedade americana de mulheres, homens e crianças aceitáveis e nenhuma deseja adentrála". Este status de marginal está frequentemente ligado a um corpo que o patriarcado considera inferior ou anormal. Conforme afirma Duarte (1999 apud FEITOSA, 2011, p. 61), as obras de Luft, em geral "tematizam o universo feminino, onde a mulher representa sempre o lado fraco de uma sociedade repressora e injusta, vítima das relações de gênero, marcada ora pela loucura, a doença ou a morte"

Portanto, ao apresentar mulheres fora da norma, isto é, mulheres grotescas, seus traumas e seus sofrimentos, as literaturas de Flannery O'Connor e de Lya Luft expõem a experiência feminina de um modo violento e real, dando vazão a sensações e experiências comuns a várias mulheres de contexto socioculturais diferentes.

\section{REFERÊNCIAS}

BABINEC, Lisa. Cyclical Patterns of Domination and Manipulation in Flannery O'Connor's Mother-Daughter Relationships. Flannery O’Connor Bulletin, v. 19, 1990, p. 9-29.

BAKHTIN, Mikhail. A cultura popular na Idade Média e no Renascimento: o contexto de François Rabelais. Trad. Yara Frateschi Vieira. $8^{a}$ ed. São Paulo: Hucitec, 2013.

CARUSO, Teresa (Org.). "On the subject of the feminist business": re-reading Flannery O'Connor. New York: Peter Lang, 2004.

COSTA, Maria Osana de Medeiros. A mulher, o lúdico e o grotesco em Lya Luft. São Paulo: Annablume, 1996.

CRIPPA, Giulia. O grotesco como estratégia de afirmação da produção pictórica feminina. Estudos

Feministas, Florianópolis, 11(1): 336, jan-jun/2003, pp. 113-135.

FEITOSA, André Pereira. Mulheres-monstro e espetáculos circenses: o grotesco nas narrativas de Angela Carter, Lya Luft e Susan Swan, (Tese de Doutorado) UFMG. Ano de obtenção: 2011.

GENTRY, Bruce. Flannery O'Connor's religion of the grotesque. Jackson and London: University Press of Mississippi, 1986.

GILBERT, Sandra M.; GUBAR, Susan. The Madwoman in the Attic: The Woman Writer and the Nineteenth Century Literary Imagination. 2 ed. New Haven and London: Yela University Press, 2000. 
HARVID, David. The saving rape: Flannery O'Connor and patriarchal religion. The Mississippi Quarterly. 47.1, Winter 1993, p. 15.

Disponível em: <http://www.missq.msstate.edu/>

Acesso em: 23 abr. 2015

KAISER, Gerhard R. Introdução à Literatura Comparada. Trad. Teresa Alegre. Lisboa: Fundação Calouste Gulbenkian, 1989

LUFT, Lya. O tigre na sombra. Rio de Janeiro: Record, 2012.

MACHADO, Álvaro Manuel; PAGEAUX, Daniel-Henri. Da literatura comparada à teoria da literatura. Lisboa: 70, 1988

O'CONNOR, Flannery. Collected Works. New York: The Library of America, 1988.

O'CONNOR, Flannery. Contos completos: Flannery O'Connor. Trad. Leonardo Fróes. São Paulo: Cosac Naify, 2008.

RUSSO, Mary. O grotesco feminino: risco, excesso e modernidade. Trad. Talita M. Rodrigues. Rio de Janeiro: Rocco, 2000.

XAVIER, Elódia. Narrativa de autoria feminina na literatura brasileira: as marcas da trajetória. Mulheres e Literatura, v. 3, 1999.

Disponível em: <http://www.letras.ufrj.br/litcult/revista_mulheres/volume3/31_elodia.html>

Acesso em: 23 ago. 2004

WILSON, Natalie. Misfit Bodies and Errant Gender: The Corporeal Feminism of Flannery O'Connor. In:

CARUSO, Teresa (Org.). "On the subject of the feminist business": re-reading Flannery O'Connor. New York, NY: Peter Lang, 2004, p. 94-119.

YAEGER, Patricia. Dirt and Desire: Reconstructing Southern Women's Writing, 1930-1990. Chicago: The University of Chicago Press, 2000. 